\title{
Prevention of diabetic eye disease: the commonest cause of blindness in individuals younger than 65 years
}

This article was published in the following Dove Press journal:

Clinical Ophthalmology

12 November 2010

Number of times this article has been viewed

\author{
Patrizio Tatti ${ }^{1}$ \\ Patrizia Di Mauro' \\ Leonardo Masselli' \\ Adriano Longobardi ${ }^{2}$ \\ Annabel Barber ${ }^{3}$ \\ 'Diabetes and Endocrinology \\ Department, ${ }^{2}$ UOS Eye Surgery, \\ Ospedale S Giuseppe, ASL RMH, \\ Rome, Italy; ${ }^{3}$ University of Nevada \\ School of Medicine, Las Vegas, \\ NV, USA
}

Correspondence: Patrizio Tatti

Diabetes and Endocrinology Department, Ospedale S Giuseppe, Marino,

(Rome) 00047, Italy

Fax +390693273563

Email info@patriziotatti.it
Abstract: There has been a considerable advancement in the treatment of diabetes and understanding of the biochemical mechanisms underlying diabetic complications in the last 20 years. However, this advancement has not translated into a consistent reduction in diabetic retinopathy, one of the most frightening complications of diabetes mellitus. It is probable that greater attention to preventive intervention will help reduce the damage load in the next future, and that several drugs for the treatment of more advanced stages of diabetic retinopathy will become available. Competent strategies targeting prevention based on screening programs should be proposed to reduce the burden and to improve the clinical outcome of this devastating diabetes complication.

Keywords: blindness, diabetes, eye disease, prevention

\section{Epidemiology}

Although there have been advancements in the treatment of diabetes in recent years, diabetic retinopathy (DR) remains the most common cause of blindness among adults. According to the Wisconsin Epidemiologic Study of Diabetic Retinopathy (WESDR), $3.6 \%$ of type 1 diabetes patients and $1.6 \%$ of type 2 diabetes patients were legally blind. ${ }^{1}$ The time of disease onset is evident in type 1 diabetes patients, therefore we know with certainty that the development of DR is unusual before the fifth year of disease onset and reaches a prevalence of more than 95\% 15 years after disease onset. On the contrary, up to $20 \%$ of type 2 diabetes mellitus patients, in whom the exact time of onset of the disease is less evident, may have signs of retinopathy at the time of diagnosis, which in most cases is preceded by a long unrecognized latency period. The prevalence of DR 15 years after disease onset in type 2 diabetes mellitus patients may reach $60 \%{ }^{2}$ The UK Prospective Diabetes Study (UKPDS), a 10-year study of newly diagnosed type 2 diabetes patients, indicates that the presence of even a single aneurysm in these patients is evidence of DR, with the prevalence of this condition at diagnosis being $38 \%{ }^{2}$ Although the percentage is higher among type 1 diabetes patients, the much greater absolute number of type 2 diabetes patients with this disease indicates DR to be a devastating complication in this category. ${ }^{3}$

However, the prevalence of progressive sight-threatening retinopathy is limited to $10 \%,{ }^{4}$ which is still relatively high. The prevalence of DR of any severity in the diabetic population as a whole is approximately $30 \% .^{5}$ Furthermore, we cannot accurately predict when severe DR will progress to blindness, although hyperglycemia and hypertension are risk factors. The actual prevalence of blindness is approximately $5 \%$ (range $3 \%-7 \%$ ) and may be as high as $8 \%{ }^{4}$ 
Although there are no comparative studies, it is highly probable that the incidence of diabetes mellitus in all its forms may vary according to the local resources and standards of care. There is abundant literature demonstrating that screening programs have been highly effective in reducing the incidence and the progression of DR. ${ }^{6}$

\section{Etiology and pathogenesis}

Diabetic retinopathy tends to follow a progressive course from minor lesions to the most serious sight-threatening patterns, but there is frequently considerable overlapping. The earliest manifestations are mild and characterized by increased vascular permeability, followed by moderate to severe changes with intravascular clotting, defined as nonproliferative DR. A more advanced phase is the proliferation of new vessels, defined as proliferative DR (PDR), with impending risk of hemorrhage. An ominous manifestation is significant macular edema (clinically significant diabetic macular edema [CSDME]) caused by retinal thickening due to leaky blood vessels, which should be distinguished from mild thickness of the retina that does not have the same serious prognosis. This sight-threatening complication may supervene at any stage of the DR.

The earliest changes are a loss of retinal neurons (neurodegeneration) and disruption of the vascular structure, which is essential to the survival of the retina. ${ }^{7}$ Interruption of the integrity of retinal capillary bed, which allows the exchange of nutrients with the retina, leads to protein leakage and the appearance of exudates, which are among the early signs of DR. It is highly probable that the hyperglycemia in diabetes leads to an array of metabolic changes, many of which may be directed toward limitation or repair of the damage. Unfortunately this hypothesis has not yet been accepted. All the above factors and possibly some other unknown factors interact to cause DR, and it is not known yet which factor may be the primary cause.

The most well known structural components of retinal capillaries are the basement membrane and pericytes, which are cells that have both structural and regulatory functions. ${ }^{8}$ The disarrangement of these structures leads to weakening of the capillaries, aneurism, and protein leakage. Loss of retinal pericytes is an early feature of DR and correlates with microaneurysm. ${ }^{9}$ Other common features of early DR are the thickening of the capillary basement membrane and the increased deposition of extracellular matrix components, leading to the development of abnormal retinal hemodynamics. ${ }^{10}$ A subsequent intervention of blood cells that clog the capillaries and lead to occlusion is probably the body's misguided attempt at damage limitation. ${ }^{11}$ There is extensive clot formation in the capillaries as the disease progresses, which interrupts blood flow and causes ischemia. In more advanced stages, there is an inordinate proliferation of blood vessels in an attempt to restore oxygen and nutrient supply to the ischemic territory. Pathogenesis of PDR is essentially due to ischemia, and pathogenesis of CSDME is due to the fluid leakage from retinal blood vessels into the area of the macula, which is rich in cones that are critical for color and daytime vision. This study mainly reviews prevention in the initial stages of the disease when medical intervention may be effective. Proliferation may be mediated by vascular endothelial growth factor (VEGF), which will be discussed later.

The etiology of DR is complex and predisposing factors are as follows: 1) duration of diabetes, ${ }^{12}$ 2) poor glucose control, ${ }^{13} 3$ ) hypertension, ${ }^{14,15} 4$ ) pregnancy, ${ }^{16,17} 5$ ) puberty, ${ }^{18}$ 6) renal disease ${ }^{19}$ (the relation between kidney and retina is so relevant that the diagnosis of diabetic nephropathy should always be questioned in the absence of a DR), and 7) hyperlipidemia ${ }^{20}$ (believed to play a role in this complication, although this hypothesis has not been confirmed). ${ }^{21}$ These factors will be discussed in detail.

The pathogenesis of DR includes both systemic and local factors, but we still do not know the exact influence of and role played by each in the different stages of the disease.

\section{Duration of diabetes}

The duration of diabetes is probably the strongest predictor of progression to $\mathrm{DR},{ }^{6}$ but is not clinically helpful in most cases of type 2 diabetes because diagnosis is delayed and the time of onset of the disease is unknown. The WESDR showed that incidence of retinopathy increased progressively from $8 \% 5$ years after disease onset to $80 \%$ after 15 years. ${ }^{22}$ The recognition of the role of disease duration is one more argument in favor of those interventions that may delay the onset of diabetes. After disease onset nothing can be done to reduce this risk factor.

\section{Hyperglycemia}

The role of hyperglycemia was proven by two landmark studies. The Diabetes Control and Complications Trial (DCCT), a study of 1441 type 1 diabetes patients randomly assigned to intensive and conventional treatment groups with different glycosylated hemoglobin $\left(\mathrm{HbA}_{1 \mathrm{c}}\right)$ levels, conclusively demonstrated that good control plays a critical role in the prevention of DR. In the intensively treated group, there was a reduction of $76 \%$ in the risk of progression. 
The patients were assigned to a primary prevention group (those with no signs of retinopathy) and a secondary prevention group (those with retinopathy) according to the status of their retina. Those in the primary prevention cohort had a similar cumulative incidence of retinopathy progression in the conventional and intensive arms untill 36 months, and then intensive treatment reduced the risk of retinopathy by $76 \%$. The intensive group in the secondary intervention cohort fared worse than the nonintensive group during the first 18 months; a phenomenon largely offset by a much greater long-term improvement with a reduced risk of $54 \%$ by 36 months. ${ }^{13}$ The results of the Epidemiology of Diabetes Interventions and Complications study, a follow-up study to the DCCT, are interesting from a theoretical perspective because there was no further attempt to use intensive treatment and the $\mathrm{HbA}_{10}$ levels of the two groups were nearly the same. Even after 5 years, outcome of the intensive therapy was favorable. ${ }^{23}$ This phenomenon is termed a 'legacy effect'. The data were deemed so relevant that, subsequently, the level of fasting blood glucose at which retinopathy appeared was included in the current criteria for the diagnosis of diabetes mellitus. In a recent study on the association of glycated $\mathrm{HbA}_{1 \mathrm{c}}$ and fasting plasma glucose (FPG) with the diagnosis of diabetes mellitus, the authors found that the highest increase in the prevalence of retinopathy occurs among individuals with $\mathrm{HbA}_{1 \mathrm{c}} \geq 5.5$ and $\mathrm{FPG} \geq 5.8 \mathrm{mmol} / \mathrm{L}$, and that, based on the areas under the receiver operating characteristic curves, $\mathrm{HbA}_{1 \mathrm{c}}$ was found to be a strong discriminator of retinopathy. ${ }^{24}$

With a protocol similar to that of the DCCT, the UKPDS randomly assigned 3867 newly diagnosed type 2 diabetes patients to an intensive or conventional treatment group and found a statistically significant $25 \%$ reduction in microvascular complications including the need for photocoagulation of the retina. This is a much more crude result than in the DCCT because the impact on each complication was not clearly determined and favored lowering blood glucose levels. An epidemiological analysis of the UKPDS data demonstrated the existence of a continuous relationship between the risk of microvascular complications and blood glucose level; for each percentage point decrease in $\mathrm{HbA}_{1 \mathrm{c}}$, the relative risk of microvascular complication was reduced by $35 \% .{ }^{25} \mathrm{~A}$ follow-up of the UKPDS subjects, analogous to that of the DCCT, demonstrated the existence of the legacy effect, with a $24 \%$ reduction in the risk of microvascular complications. ${ }^{26}$

The Veterans Affairs Diabetes Trial (VADT) that followed a different population of 1791 older diabetic veterans, mostly men, for a median of 5.6 years did not find any effect from intensive glucose control on retinopathy (progression to proliferative disease, macular edema, increase in severity of disease, and new onset of disease; all $P=$ not specified $[\mathrm{NS}]) .{ }^{27}$ Similar results were obtained for the ADVANCE (Action in Diabetes and Vascular Disease: Preterax and Diamicron MR Controlled Evaluation) study in which there were no changes in the rate of severe retinopathy. ${ }^{28}$ Taken together, these observations suggest that the effect of good glycemic control is most evident at disease onset when harmful microvascular complications can set in. Any later intervention is likely to have only modest beneficial effect. This is confirmed by the UKPDS observation that a favorable legacy effect of glucose control was found in newly diagnosed subjects which lasted until follow-up. ${ }^{26}$ However, the VADT and ADVANCE studies in a longstanding diabetic population did not find any significant effect.

The exact mechanisms that cause persistent hyperglycemia to become DR are still partially unknown, however, the polyol pathway has been found to play a prominent role. ${ }^{28}$ The polyol pathway is dependent on the glucose overload to the noninsulin-dependent cells such as cells of the eye. ${ }^{29}$ This pathway leads to the intracellular accumulation of sorbitol and fructose..$^{30}$ It has been demonstrated that the increase in aldose reductase activity within the retinal cells contributes to oxidative stress and overexpression of VEGF protein. ${ }^{31}$ Furthermore, an increased frequency of the Z-2 allele of the aldose reductase gene in diabetes patients with DR vs those without DR $\left(39.1 \%\right.$ vs $\left.26.5 \% ; \chi^{2}=6.9\right)$ has been demonstrated, which partially explains the role of genetics in this complication. ${ }^{31,32}$ Modest results were obtained in therapeutic trials with aldose reductase inhibitors that reduce the efficiency of the polyol pathway, and one of these substances purported to be beneficial for diabetic neuropathy has now been withdrawn from the market for proven negative cost-tobenefit ratio. ${ }^{33,34}$ Furthermore, these drugs have frequent and potential dangerous side effects (liver and kidney damage).

Increased oxidative stress causes a characteristic endothelial dysfunction, which has been observed in diabetes patients and normal subjects. ${ }^{35,36}$ Brownlee and colleagues demonstrated that damage can be reversed by suppression of intracellular free radicals with manganese superoxide dismutase, which has an antioxidant effect. ${ }^{37}$ Another important and still not totally explored aspect is that oxygen-free radicals can activate nuclear factor $\kappa \mathrm{B}$ and in turn many genes related to vascular stress response. ${ }^{38}$ One disappointing aspect is that clinical trials with vitamin $\mathrm{E}$, a potent antioxidant, failed to demonstrate beneficial effects. ${ }^{39}$ This failure 
could be explained by the fact that since vitamin E only acts by scavenging already formed oxidants in this antioxidant therapy, this therapy may be a more "symptomatic" rather than causal treatment for vascular oxidative stress. ${ }^{40}$

The formation of advanced glycation end products (AGEs) may also have a role. These compounds result from the nonenzymatic binding of glucose to protein side chains. ${ }^{41}$ Accumulation of these protein side chains in the capillaries of the retina leads to loss of pericytes, causing blood-retinal barrier dysfunction, increasing synthesis of VEGF in the retina, ${ }^{42}$ and increasing monocyte adhesion to the retinal endothelial cells through an increase in the expression of intercellular adhesion molecule $1 .{ }^{43}$ Aminoguanidine, an inhibitor of AGE formation, appears to reduce the early histological changes in the retina. However, the drug causes anemia in humans. ${ }^{44}$

Another mechanism of damage is the activation of the protein kinase $\mathrm{C}$ (PKC) family pathway. ${ }^{45}$ This pathway is a consequence of hyperglycemia and has a role in the pathogenesis of DR. ${ }^{46}$ The main isoform implicated is PKC- $\beta 2$, which causes hyperexpression of endothelin, increased vascular permeability, alterations in renal blood flow, and in vitro stimulations of VEGF secretion. ${ }^{47}$ Two drugs with inhibitory effect have been developed, ruboxistaurin (Eli Lilly, Indianapolis, IN) and midostaurin, but their effectiveness is still uncertain. ${ }^{48}$ Brownlee recently put forth a unifying theory according to which glucose overload flowing through the glycolytic pathway could cause a kind of "collateral damage" consisting of superoxide production in endothelial cells at the mitochondrial level. The superoxide could cause DNA damage in turn, and the consequent attempt to repair the damage could start the aforementioned dangerous cascades involved in diabetes complications. ${ }^{49}$ The existence of all these pathways leading to diabetic complications led to the search for antioxidant compounds that are still in the pipeline or in early experimental stages. Among the available compounds, lipoic acid is purported to have the ability to restore endothelial function in diabetes. ${ }^{50}$ As will be dealt with later, other commonly used drugs such as thiazolidinediones, statins, angiotensin-converting enzyme inhibitors (ACEI), and angiotensin type 1 (AT1) receptor blockers may also have potent antioxidant effects, although there are no evident conclusive results for the protection of the retina.

An increase in VEGF, a family of proteins mitogenic for vascular endothelial cells that increase vascular permeability, has been demonstrated in DR. ${ }^{51}$ The knowledge of the role of these substances led to extensive research on its antagonists. The systemic administration of these antagonists might cause serious damage by blocking angiogenesis, impairing the response to ischemic events, worsening peripheral ischemia, increasing proteinuria, and impairing wound healing process, ${ }^{52}$ and hence the use of these agents is restricted to intravitreal administration. However, a backflow is possible from the vitreal chamber to the systemic circulation. ${ }^{53}$ It has yet to be proven that these agents for intravitreal administration are preferred over triamcinolone acetonide.

Other growth factors of interest are growth hormone (GH) and insulin-like growth factor-1 (IGF-1). Hypophysectomy was performed in advanced DR in the past, ${ }^{54}$ with a good rate of regression. Further evidence for the role of GH or IGF-I comes from the observation of the increased rate of appearance and progression of the DR in puberty and pregnancy, which are stages of increased GH secretion. ${ }^{55}$ The GH antagonist, pegvisomant, has been used to induce regression of neovascularization, with a negative outcome. ${ }^{56}$ Octreotide, a somatostatin analog, decreases the need for photocoagulation. ${ }^{57}$

Although the literature on the pathogenetic mechanisms that lead to DR is abundant, exploiting the mechanisms did not yield fruitful results. Control of hyperglycemia proved to be the mainstay of prevention of DR and progression of the disease was able to be reversed to a certain point. In the intensive treatment of diabetes, the physicians should make any effort to avoid the risk of hypoglycemia as it is a risk factor for progression to DR. The Action to Control Cardiovascular Risk in Diabetes (ACCORD) eye study, ${ }^{58} \mathrm{a}$ subset of the ACCORD trial, was designed primarily to study the effects of intensive glycemic control on cardiovascular events in type 2 diabetes subjects. The primary outcome of 2,856 subjects was a 3-step change on a 17-step retinopathy scale (from retinal photographs) or development of PDR. After 4 years of follow-up, intensive treatment to lower the blood glucose to normal levels significantly reduced the incidence of progressive DR compared with conventional treatment that resulted in a higher $\mathrm{HbA}_{1 \mathrm{c}}$ levels $(7.3 \%$ vs $10.2 \%)$, but not vision loss (16.3\% vs $16.7 \%)$. However, the drawbacks of this study were the excess mortality and the absence of positive effects on adverse cardiovascular events in the intensive arm. Although the exact cause of the increased mortality is not known, there is general agreement that the intensive intervention to reduce the blood glucose level should be individually weighed against the risk.

We observed an unexpected improvement in the most initial forms of retinopathy while using a combination of arginine, glutamine, and hydroxy- $\beta$-butyrate coupled with an increased percentage of dietary protein for the treatment 
of diabetic foot ulcers over 14 months. This combination treatment can increase the formation of collagen fibers. The treated patients presented a reduction in the number of microaneurysms after 6 months $(20 \% ; P=0.012)$ and 12 months $(39 \% ; P=0.006)$, and retinal exudates were reduced $38.6 \%(P=0.000)$ at 6 months and $52 \%$ at 12 months $(P=0.003)$. We hypothesize that protein loss in diabetes patients through neoglycogenesis and proteinuria may cause a disarrangement of the basement membrane of the retinal capillaries, a phenomenon that was reversed by diet and the combination of drugs.

\section{Blood pressure}

There is sufficient data to validate high blood pressure as a risk factor for DR and the positive effect of blood pressure reduction on the progression of the disease. ${ }^{59}$ The UKPDS showed that intensive blood pressure control in type 2 diabetes was effective in reducing the microvascular complication associated with diabetes. Analogous to the results of blood glucose control, the initial study results released in 1997 demonstrated that an effective blood pressure control could induce a relative risk reduction of $37 \%{ }^{60}$

However, contrary to the blood glucose results, there was no legacy effect for blood pressure and the UKPDS follow-up study in 2007, 10 years after the intensive treatment had been interrupted, reported only $16 \%$ relative risk reduction in the intensive group $(P=\mathrm{NS})$. Thus, it appears that good blood pressure control must be continued to control disease progression. ${ }^{61}$

The ACCORD eye study group published the results of the effects at 4 years of either intensive or standard treatment for diabetes and dyslipidemia or for systolic blood pressure control on 2856 diabetes subjects. ${ }^{58}$ In 4 years, the rate of progression was $10.4 \%$ with intensive blood pressure lowering treatment vs $8.8 \%$ with standard therapy $(P=\mathrm{NS})$. According to the authors, intensive glycemic control and intensive combination treatment of dyslipidemia, but not intensive pressure control, reduced the rate of progression of DR.

There have been many studies on ACEI and angiotensin receptor blockers (ARBs) to investigate the existence of direct effects not mediated by blood pressure reduction. The basis for these studies is the discovery of the renin-angiotensin system in the eye ${ }^{62}$ and the in vitro binding of angiotensin II to the AT1 receptors, which causes a series of negative effects such as inflammation, oxidative stress, neoangiogenesis, and fibrosis. ${ }^{63}$ However, the in vivo studies did not confirm these observations completely. The UKPDS did not find any significant differences among patients treated with atenolol, a beta blocker, and those treated with captopril, an ACEI. However, captopril is a very old drug with a short half-life. The EUCLID study did not consider DR as a primary end-point and demonstrated that normoalbuminuric and microalbuminuric lisinopril could significantly reduce the progression of DR in normotensive diabetes patients but with no decrease in incidence. ${ }^{63}$ However, in this study, statistical significance almost disappeared after adjusting for the mean $\mathrm{HbA}_{1 \mathrm{c}}$ of the control group. Furthermore, the follow-up period was only 2 years. Thus, this study can be considered only suggestive and not conclusive. In another highly sophisticated study, the Direct Protect, in which both type 1 and 2 diabetes patients were studied for prevention and progression of DR with the ARB candesartan, the only clearly significant outcome not specified as a primary endpoint was a $34 \%$ regression $(P=0.009)$ mostly in subjects with mild disease. ${ }^{64}$ Overall, one can surmise that the benefits attributable to the current ACEI/ARB blockers are marginal or absent.

The current recommendations for control of blood glucose and hypertension are $\mathrm{HbA}_{1 \mathrm{c}}<7 \%(<6.5 \%$ according to the European Association for the Study of Diabetes) and blood pressure $\leq 130 / 80 \mathrm{~mm} \mathrm{Hg}{ }^{65}$

\section{Dyslipidemia}

Among the known risk factors, hyperlipidemia is associated with the presence of hard exudates in the retina, ${ }^{66}$ which has been confirmed by recent studies. Nathan and colleagus found a significant association of total to high-density lipoprotein (HDL) cholesterol ratio and triglycerides only on significant macular edema and hard exudates, which in itself is not proof of cause-effect. ${ }^{67}$ The Fenofibrate Intervention and Event Lowering in Diabetes study was designed to answer these questions. Fenofibrate is a peroxisome proliferator receptor (PPR)- $\alpha$ agonist that lowers triglycerides, reduces total and low-density lipoprotein (LDL) cholesterol, increases HDL cholesterol, and decreases small LDL particles and apolipoprotein B. ${ }^{67}$ Fenofibrate reduced the need for laser treatment and less consistently the progression of retinopathy. ${ }^{68}$ The effects of fenofibrate are independent of lipid levels, as demonstrated by the observation that PPR- $\alpha$ may reduce the expression of VEGF receptor $2{ }^{69}$

Although the aim of this review is limited to the pharmacological treatment of DR, it is worth mentioning that most of the effective treatments of DR now involve surgical or laser procedures. Vitrectomy laser treatments have effectively revolutionized prognosis, although there are still drawbacks. 
The correct therapeutic approach to DR can be summarized as follows: blood glucose control; fundus examination (ophthalmoscopy, retinal fluoroangiography, indocyanine green angiography, and optical coherence tomography); evaluation of the stage of progression if any; retinal laser therapy to prevent the proliferation of neovessels; or surgical therapy in growth of neovessels into the vitreous, in vitreous hemorrhage, or in fibrous tissue proliferation on the retinal surface or on the optical disc. In these cases, vitrectomy is the only methodology available to interrupt the progression of the disease, through the suction of hematic vitreous, that, if left untreated, is an obstacle to vision and supports the growth of neovessels.

Furthermore, the intravitreal injection of anti-VEGF drugs (ranibizumab, pegaptanib, bevacizumab, etc) improved the prognosis of retinal neovessels and exudative disorders.

All these observations are complicated because DR is probably not a single disease, and the dependency on different causative factors may vary according to the different stages of the disease. Clinicians may be disappointed by divergent and often conflicting study results if the studies do not consider this aspect of the disease. Furthermore, some drugs used to reduce the blood glucose may damage the retina. One example is the use of rosiglitazone, suspected of causing macular edema under certain circumstances, ${ }^{69}$ although we did not find any effect in a retrospective series. ${ }^{70}$

\section{Conclusion}

Current medical interventions may be useful if carried out early, and the effect is limited to the rate of appearance and the minor manifestations of the disease. When the disease progresses, the best treatment option is laser therapy or surgery, and is not the recommended medical treatment at present.

\section{Disclosure}

The authors report no conflicts of interest in this work.

\section{References}

1. Klein R, Klein BE, Moss SE, Davis MD, DeMets DL. The Wisconsin epidemiologic study; Part III: prevalence and risk of diabetic retinopathy when age at diagnosis is thirty or more years. Arch Ophthalmol. 1984; 102:527-533.

2. Kohener EM, Stratton IM, Aldinton SJ. Prevalence of diabetic retinopathy at diagnosis of NIDDM in the UKPDS. Invest Ophthalmol Vis Sci. 1993;34:713.

3. Mokdad AH, Ford ES, Bowman BA, et al. Diabetes trends in the US: 1990-1998. Diabetes Care. 2000;23:1278-1283.

4. Foulds WS, MacCuish AC, Barrie T. The cost effectiveness of screening for diabetic retinopathy. Semin Ophthalmol. 1987;2:45-50.
5. Scobie IN, MacCuish AC, Green FD, Foulds WS. Serious retinopathy in a diabetic clinic: prevalence and therapeutic implications. Lancet. 1981;2:520-521.

6. Garg S, Davis RM. Diabetic retinopathy screening update. Clin Diabetes. 2009;27:140-145.

7. Barber AJ. A new view of diabetic retinopathy: a neurodegenerative disease of the eye. Prog Neuropsychopharmacol Biol Psychiatry. 2003; 27:283-290.

8. Antonelli-Orlidge A, Smith SR, D'Amore PA. Influence of pericytes on capillary endothelial cell growth. Am Rev Respir Dis. 1989;140: 1129-1131.

9. Speiser P, Gittelsohn AM, Patz A. Studies on diabetic retinopathy; Part III: influence of diabetes on intramural pericytes. Arch Ophthalmol. 1968;80:332-337.

10. Mogensen CE, Osterby R, Gundersen HJ. Early functional and morphologic vascular renal consequences of the diabetic state. Diabetologia. 1979;17:71-76.

11. Miyamoto K, Ogura Y. Pathogenetic potential of leukocytes in diabetic retinopathy. Semin Ophthalmol. 1999;14:233-239.

12. Rand LI, Krolewski AS, Aiello LM, Warram JH, Baker RS, Maki T. Multiple factors in the prediction of risk of proliferative diabetic retinopathy. N Engl J Med. 1985;313:1433-1437.

13. The effect of intensive treatment of diabetes on the development and progression of long-term complications in insulin-dependent diabetes mellitus. The Diabetes Control and Complications Trial Research Group. N Engl J Med. 1993;329:977-986.

14. Knowler WC, Bennett PH, Ballintine EJ. Increased incidence of retinopathy in diabetics with elevated blood pressure. $N$ Engl J Med. 1980;302:645-650.

15. Klein R, Klein BE, Moss SE, Davis MD, DeMets DL. Is blood pressure a predictor of the incidence and progression of diabetic retinopathy? Arch Intern Med. 1989;149:2427-2432.

16. Moloney JB, Drury MI. The effect of pregnancy on the natural course of diabetic retinopathy. Am J Ophthalmol. 1982;93:745-756.

17. Klein BE, Moss SE, Klein R. Effect of pregnancy on progression of diabetic retinopathy. Diabetes Care. 1990;13:34-40.

18. Dorchy H. Screening for subclinical diabetic complications in young type 1 diabetic patients: experience acquired in Brussels. Pediatr Endocrinol Rev. 2004;1:380-403.

19. Aiello LP, Cahill MT, Wong JS. Systemic considerations in the management of diabetic retinopathy. Am J Ophthalmol. 2001;132:760-776.

20. Klein BE, Moss SE, Klein R, Surawicz TS. Serum cholesterol in the Wisconsin epidemiologic study of diabetic retinopathy. Diabetes Care. 1992;15:282-287.

21. Leung H, Wang JJ, Rochtchina E, Wong TY, Klein R, Mitchell P. Dyslipidaemia and microvascular disease in the retina. Eye (Lond). 2005; 19:861-868.

22. Brown JB, Pedula KL, Summers KH. Diabetic retinopathy. Diabetes Care. 2003;26:2637-2642.

23. Retinopathy and nephropathy in patients with type I diabetes four years after a trail of intensive therapy. The Diabetes Control and Complications Trial/Epidemiology of Diabetes and Complications Research Group. N Engl J Med. 2000;342:381-389.

24. Yiling J, Cheng J. Association of A1C and fasting plasma glucose levels with diabetic retinopathy prevalence in the US population. Diabetes Care. 2009;32:2027-2032.

25. Intensive blood-glucose control with sulphonylureas or insulin compared with conventional treatment and risk of complications in patients with type 2 diabetes (UKPDS 33). UK Prospective Diabetes Study (UKPDS) Group. Lancet. 1998;352:837-853.

26. Holman RR, Paul SK, Bethel MA, Matthews DR, Neil HA. 10-year follow-up of intensive glucose control in type 2 diabetes. NEngl J Med. 2008;359:1577-1589.

27. Duckworth W, Abraira C, Moritz T, et al; VADT Investigators. Glucose control and vascular complications in veterans with type 2 diabetes. N Engl J Med. 2009;360:129-139. 
28. Patel A, MacMahon S, et al; ADVANCE Collaborative Group. Intensive blood glucose control and vascular outcomes in patients with type 2 diabetes. N Engl J Med. 2008;358:2560-2572.

29. Obrosova IG, Minchenko AG, Vasupuram R, et al. Aldose reductase inhibitor fidalrestat prevents retinal oxidative stress and vascular endothelial growth factor overexpression in streptozotocin diabetic rats. Diabetes. 2003;52:864-871.

30. Abhary S, Burdon KP, Laurie KJ, et al. Aldose reductase gene polymorphisms and diabetic retinopathy susceptibility. Diabetes Care. 2010;33:1834-1836.

31. Obrosova IG, van Huysen C, Fathallah L, Cao XC, Greene DA, Stevens MJ. An aldose reductase inhibitor reverses early diabetes-induced changes in peripheral nerve function, metabolism and antioxidative defense. FASEB J. 2002;16:123-125.

32. Petrovic MG, Peterlin B, Hawlina M, Petrovic D. Aldose reductase (AC)n gene polymorphism and susceptibility to diabetic retinopathy in type 2 diabetes in Caucasians. J Diabetes Complications. 2005;19: 70-73.

33. Tromp A, Hooymans JM, Barendsen BC, van Doormaal JJ. The effects of an aldose reductase inhibitor on the progression of diabetic retinopathy. Doc Ophthalmol. 1991;78:153-159.

34. van Gerven JM, Boot JP, Lemkes HH, van Best JA. Effects of aldose reductase inhibition with tolrestat on diabetic retinopathy in a six months double blind trial. Doc Ophthalmol. 1994;87:355-365.

35. Ceriello A. New insights on oxidative stress and diabetic complications may lead to a causal antioxidant therapy. Diabetes Care. 2003;26: 1589-1596.

36. Giugliano D, Marfella R, Coppola L, et al. Vascular effects of acute hyperglycemia in humans are reversed by L-arginine: evidence for reduced availability of nitric oxide during hyperglycemia. Circulation. 1997;95:1783-1790.

37. Nishikawa T, Brownlee M. Normalizing mitochondrial superoxide production blocks three pathways of hyperglycaemic damage. Nature. 2000;404:787-790.

38. Collins T. Endothelial nuclear factor $\mathrm{kB}$ and the initiation of the atherosclerotic lesion. Lab Invest. 1993;68:499-508.

39. Marchioli R, Schweiger C, Levantesi G, Tavazzi L, Valagussa F. Antioxidant vitamins and prevention of cardiovascular disease: epidemiological and clinical trial data. Lipids. 2001;36:S53-S63.

40. Cuzzocrea S. Antioxidant therapy: a new pharmacological approach in shock, inflammation, and ischemia /reperfusion injury. Pharmacol Rev. 2001;53:135-159.

41. Wautier JL, Guillausseau PJ. Advanced glycation end products, their receptors and diabetic angiopathy. Diabetes Metab. 2001;27: 535-542.

42. Stitt AW, Bhaduri T, McMullen CB, Gardiner TA, Archer DB. Advanced glycation end products induce blood-retinal barrier dysfunction in normoglycemic rat. Mol Cell Biol Res Commun. 2000;3: 380-388.

43. Mamputu JC, Renier G. Advanced glycation end-products increase monocyte adhesion to retinal endothelial cells through vascular endothelial growth factor-induced ICAM-1 expression: inhibitory effect of antioxidants. J Leukoc Biol. 2004;75:1062-1069.

44. Zhang Q, Zhang J, Guan Y, et al. Suppression of retinal neovascularization by the iNOS inhibitor aminoguanidine in mice of oxygeninduced retinopathy. Graefes Arch Clin Exp Ophthalmol. 2009;247: 919-927.

45. Danis RP, Bingaman DP, Jirousek M, Yang Y. Inhibition of intraocular neovascularization caused by retinal ischemia in pigs by PKCbeta inhibition with LY333531. Invest Ophthalmol Vis Sci. 1998;39: 171-179.

46. Ways DK, Sheetz MJ. The role of protein kinase C in the development of the complications of diabetes. Vitam Horm. 2000;60:149-193.

47. Shiba T, Inoguchi T, Sportsman JR, Heath WF, Bursell S, King GL. Correlation of diacylglycerol level and protein kinase $\mathrm{C}$ activity in rat retina to retinal circulation. Am J Physiol. 1993;265:E783-E793.
48. Aiello LP, Davis MD, et al; PKC-DRS2 Group. Effect of ruboxistaurin on visual loss in patients with diabetic retinopathy. Ophthalmology. 2006;113:2221-2230.

49. Brownlee M. The pathobiology of diabetic complications: a unifying mechanism. Diabetes. 2005;54:1615-1625.

50. Hetizer T, Finckh B, Albers S, Krohn K, Kohlschütter A, Meinertz T. Beneficial effects of alpha-lipoic acid and ascorbic acid on endothelium-dependent, nitric oxidemediated vasodilation in diabetic patients relation to parameters of oxidative stress. Free Radic Biol Med. 2001;31:53-61.

51. Aiello LP, Avery RL, Arrigg PG, et al. Vascular endothelial growth factor in ocular fluid of patients with diabetic retinopathy and other retinal disorders. $N$ Engl J Med. 1994;331:1480-1487.

52. Simó R, Hernandez C. Intravitreous antiVEGF for diabetic retinopathy: hopes and fears for a new therapeutic strategy. Diabetologia. 2008;51: 1574-1580.

53. Wirostko B, Wong TY, Simó R. Vascular endothelial growth factor and diabetic complications. Prog Retin Eye Res. 2008;27:608-621.

54. Sharp PS, Fallon TJ, Brazier OJ, Sandler L, Joplin GF, Kohner EM. Long-term follow-up of patients who underwent yttrium-90 pituitary implantation for treatment of proliferative diabetic retinopathy. Diabetologia. 1987;30:199-207.

55. Chantelau E. Evidence that upregulation of serum IGF-1 concentration causes acceleration of diabetic retinopathy. Br J Ophthalmol. 1998;82: 725-730.

56. Growth Hormone Antagonist for Proliferative Diabetic Retinopathy Study Group. The effect of a growth hormone receptor antagonist drug on proliferative diabetic retinopathy. Ophthalmology. 2001;108: 2266-2272.

57. Grant MB, Mames RN, Fitzgerald C, et al. The efficacy of octreotide in the therapy of severe nonproliferative and early proliferative diabetic retinopathy: a randomized controlled study. Diabetes Care. 2000;23: 504-509.

58. Chew EY, et al; ACCORD Study Group, ACCORD Eye Study Group. Effects of medical therapies on retinopathy progression in type 2 diabetes. $N$ Engl J Med. 2010;363:233-234.

59. Tight blood pressure control and risk of macrovascular and microvascular complications in type 2 diabetes: UKPDS 38. UK Prospective Diabetes Study Group. Br Med J. 1998;317:703-713.

60. Adler A, Stratton IM, Neil HA, et al. Association of systolic blood pressure with macrovascular and microvascular complications of type 2 diabetes (UKPDS 36): prospective observational study. BMJ. 2000; $321: 412-419$.

61. Chalmers J, Cooper ME. UKPDS and the legacy effect. $N$ Engl J Med. 2008;359:1616-1620.

62. Moravski CJ, Skinner SL, Stubbs AJ, et al. The renin-angiotensin system influences ocular endothelial cell proliferation in diabetes: transgenic and interventional studies. Am J Pathol. 2003;162:151-160.

63. Chaturvedi N, Sjolie AK, Stephenson JM, et al. Effect of lisinopril on progression of retinopathy in normotensive people with type 1 diabetes. The EUCLID Study Group. EURODIAB Controlled Trial of Lisinopril in Insulin-Dependent Diabetes Mellitus. Lancet. 1998;351: 28-31.

64. Sjølie AK, Klein R, Porta M, et al; DIRECT Programme Study Group. Effect of candesartan on progression and regression of retinopathy in type 2 diabetes (DIRECT-Protect 2): a randomised placebo-controlled trial. Lancet. 2008;372:1385-1393.

65. American Medical Association. Standards of medical care in diabetes2010. Diabetes Care. 2010;33 (Supp1 1):S11-S61.

66. Klein BE, Moss SE, Klein R, Surawicz TS. The Wisconsin Epidemiologic Study of Diabetic Retinopathy. XIII. Relationship of serum cholesterol to retinopathy hard exudate. Ophthalmology. 1991;98: 1261-1265.

67. Miljanovic B, Glynn RJ, Nathan DM, Manson JE, Schaumberg DA. A prospective study of serum lipids and risk of diabetic macular edema in type 1 diabetes. Diabetes. 2004;5:2883-2892. 
68. Keech AC, Mitchell P, Summanen PA, et al; FIELD Study Investigators. Effect of fenofibrate on the need for laser treatment for diabetic retinopathy (FIELD study): a randomized controlled trial. Lancet. 2007;370:1687-1697.

69. Meissner M, Stein M, Urbich C, et al. PPARalpha activators inhibit vascular endothelial growth factor receptor-2 expression by repressing Sp1-dependent DNA binding and transactivation. Circ Res. 2004;94:324-332.
70. Tatti P, Arrigoni F, Longobardi A, Costanza F, di Blasi P, Merante D. Retrospective analysis of rosiglitazone and macular oedema in patients with type 2 diabetes mellitus. Clin Drug Invest. 2008;28: 327-332.

71. Poster presentation. ESPEN 2010, Nice, 2010 Oct 2-5.
Clinical Ophthalmology

\section{Publish your work in this journal}

Clinical Ophthalmology is an international, peer-reviewed journal covering all subspecialties within ophthalmology. Key topics include: Optometry; Visual science; Pharmacology and drug therapy in eye diseases; Basic Sciences; Primary and Secondary eye care; Patient Safety and Quality of Care Improvements. This journal is indexed on

\section{Dovepress}

PubMed Central and CAS, and is the official journal of The Society of Clinical Ophthalmology (SCO). The manuscript management system is completely online and includes a very quick and fair peer-review system, which is all easy to use. Visit http://www.dovepress.com/ testimonials.php to read real quotes from published authors. 